\title{
Fundus flavimaculatus: polymorphic retinal change in siblings
}

\author{
Y ISASHIKI AND N OHBA \\ From the Department of Ophthalmology, Kagoshima University Faculty of Medicine, Kagoshima-shi, \\ Japan (890)
}

SUMMARY A 12-year-old boy and an 11-year-old girl, siblings of healthy, consanguineous parents, had a bilateral retinal dystrophy with a gradual loss of vision. The brother showed a bull's eye macular change with sparse fundus flavimaculatus type flecks. The sister had numerous fleck lesions of fundus flavimaculatus throughout the posterior fundus, but there was virtually no macular change. Thus the siblings presented instances of polymorphic expressivity of fundus flavimaculatus.

The classification of hereditary macular degeneration is based on knowledge of the genetic, morphological, and functional abnormalities, but controversy has existed on the identification of some disease conditions. If a polymorphic macular change is found among members of a given family, the abnormality probably indicates the variable expressivity of a genetically identical disease. We describe a pedigree in which two siblings of consanguineous parents showed bull's eye macular change with sparse fleck lesions of fundus flavimaculatus type and fundus flavimaculatus without macular involvement, respectively.

\section{Case reports}

The patients are a brother and sister who are two of three children of first-cousin consanguineous parents (Fig. 1). The parents and their youngest child, aged 9 years, were examined and found to be normal. Family members of the parents live in the southwest region of Kyushu island of Japan. None of the accessible relatives were willing to come for examination, but according to information obtained from the parents no other relatives are affected with any hereditary ocular disease.

CASE 1

A 12-year-old boy was born in 1972 after a uneventful delivery, and had been well in general health. He was

Correspondence to Norio Ohba, MD, Department of Ophthalmology, Kagoshima University Faculty of Medicine, Usuki-cho 1208-1, Kagoshima-shi, Japan (890)). referred to us for investigation of a gradual loss of vision; according to his history the visual acuity at 7 years was 0.8 in both eyes, followed by a gradual diminution. He complained of bilateral blurred vision, but had no photophobia. On examination the visual acuity was 0.1 in both eyes, which was not correctable with either glasses or contact lenses. There were no refractive errors. Goldmann perimetric tests showed in both eyes a dense central

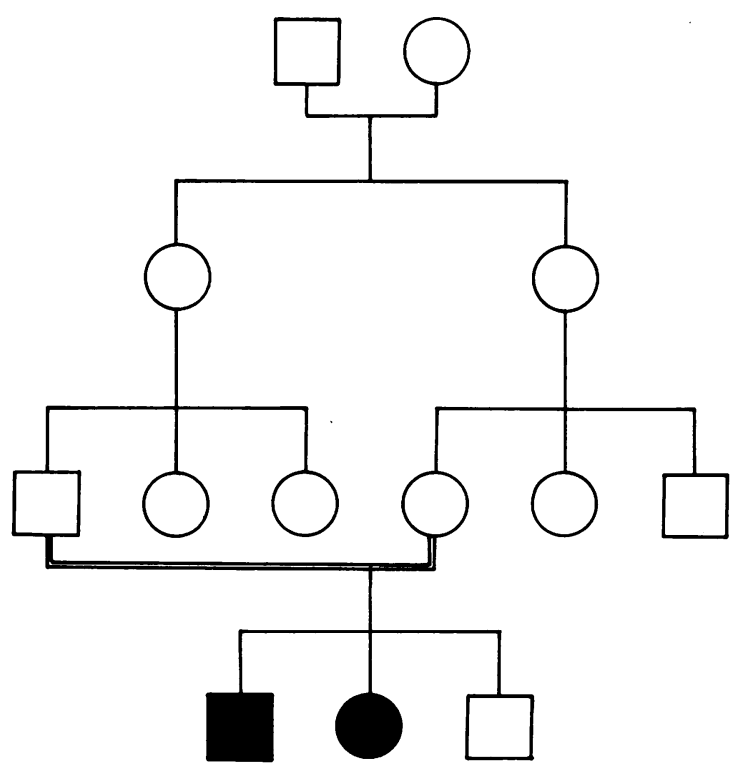

Fig. 1 Pedigree of the family. 


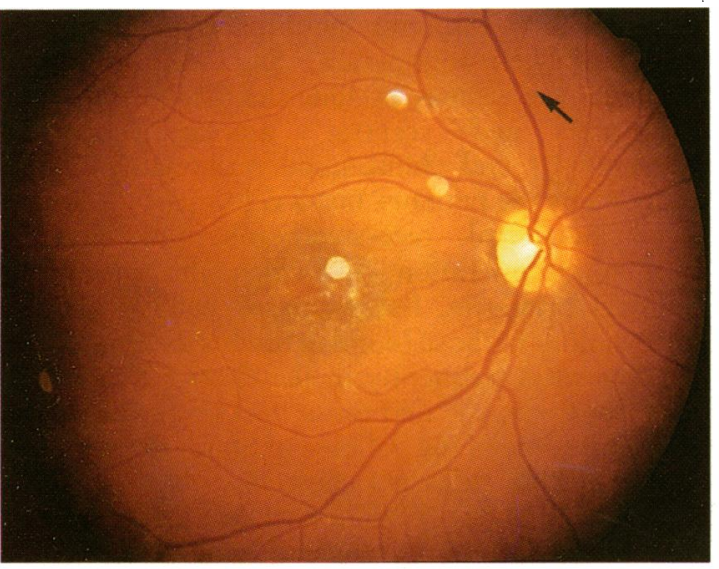

Fig. 2A

Fig. 2 Right fundus of case I (brother). (A) April 1983,(B) June 1984. Bull's eye maculopathy. Arrows indicate fleck lesions of fundus flavimaculatus type.

scotoma of about $10^{\circ}$, but the peripheral visual fields were normal. The Farnsworth panel D-15 test revealed a tritan defect, and the Farnsworth-Munsell 100-hue test showed a total error score of 188 with non-specific axis. He had no difficulty in night vision. The photopic and scotopic electroretinograms were normal. The ocular anterior segments and media were normal.

Ophthalmoscopic examination showed bilateral, symmetrical change of the macular region, in which there was a horizontal, oval, well defined atrophic lesion measuring 2 disc diameters in width and 1.5 disc diameters in height, having a beaten-bronze metallic appearance. A few yellowish white, ill defined flecks were deposited in the deep retina of the posterior fundus. The retinal vessels and optic discs

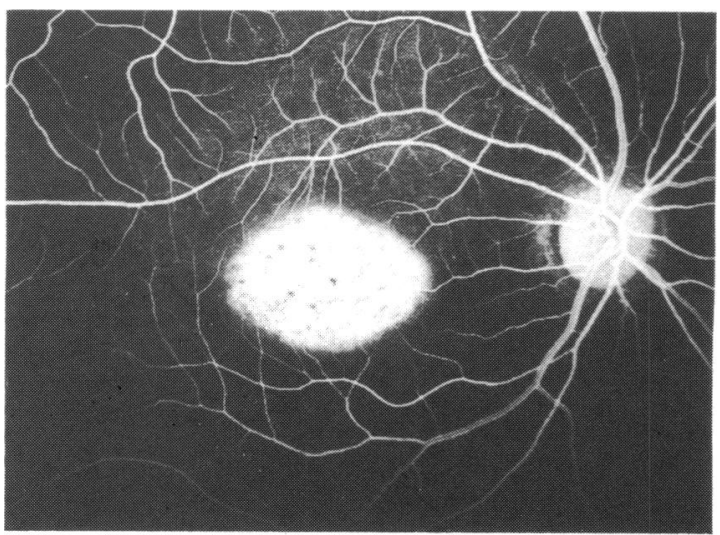

Fig. 3 Fluorescein angiogram of right fundus of case I (June 1984).

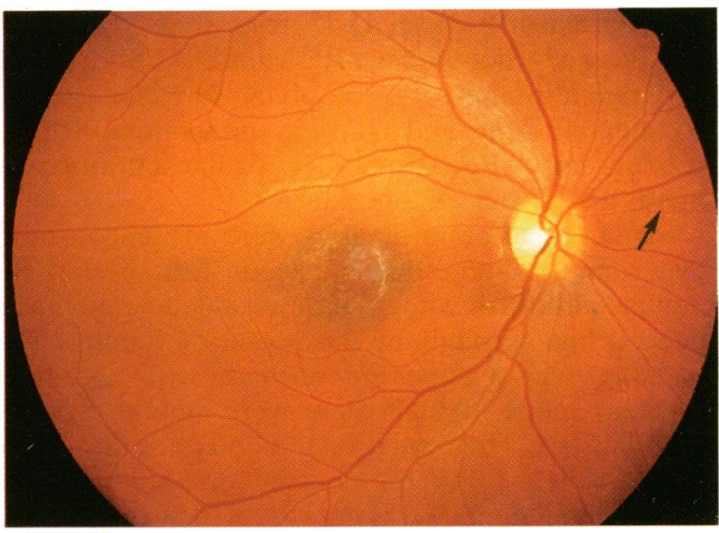

Fig. 2B

were normal. The fluorescein angiograms revealed a dark choroid with a central ovoid zone of hyperfluorescence due to atrophy of the pigment epithelium, presenting a bull's eye macular change.

Follow-up observations 14 months later showed an increasing number of flecks of fundus flavimaculatus type, though they were not so conspicuous as in case 2 . The bull's eye macular lesions remained unchanged (Figs. 2A, 2B, 3).

\section{CASE 2}

An 11-year-old girl, sister of case 1, was born in 1973 without any history of abnormality during gestation and delivery, and had developed well. She was referred to us together with her brother for investigation of a gradual loss of bilateral vision. She had no difficulty in night vision. On examination the refractions were normal, and the visual acuity was $0 \cdot 1$ in both eyes, which was not correctable with glasses. Goldmann perimetry showed in both eyes a small, weak central scotoma with normal peripheral fields.

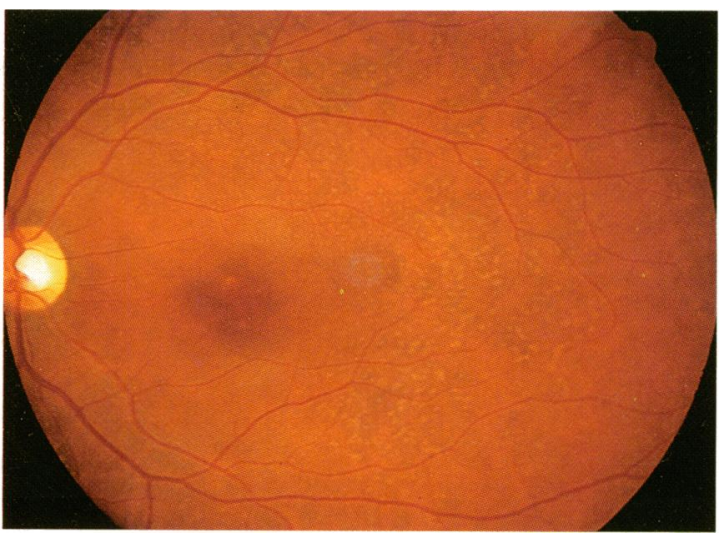

Fig. 4 Left fundus of case 2 (sister). Fundus flavimaculatus. 
The Farnsworth panel D-15 tests showed a tritan defect, and the Farnsworth-Munsell 100-hue test revealed a total error score of 430 with non-specific colour confusion. The photopic and scotopic electroretinograms were normal. The ocular anterior segments and media were normal.

Symmetrical abnormalities were present in both eyegrounds. Numerous linear or fishtail-like, illdefined yellowish white flecks were deposited in the deep retina throughout the posterior fundus. The macular region appeared normal, with an intact foveolar reflex, though there were minute pigment granularities. The retinal vessels and optic discs were normal (Fig. 4). Fluorescein angiographic study was recommended, but it was not accepted by the patient. Follow-up 14 months later showed no substantial changes in the fundus.

\section{Discussion}

It is evident that the siblings described above had a polymorphic dystrophic change in the retina.

The bilateral macular degeneration of one sibling, case 2 (sister), is consistent with fundus flavimaculatus, a term first introduced by Franceschetti' to describe an autosomal, recessively inherited, bilateral retinal degeneration in which white or yellowish white, round or linear ill-defined flecks are scattered in the deep retina of the posterior fundus with frequent association of macular degeneration. ${ }^{23}$ This case is consistent with the 'pure form' of fundus flavimaculatus without macular involvement, ${ }^{24}$ though minute pigment granularities in the fovea may suggest an early macular degeneration and account for the reduced visual acuity.

The bilateral macular change in case 1 (brother) is characterised by bull's eye lesions with a beatenbronze atrophic appearance. The bull's eye macular change has been known to occur in a variety of hereditary retinochoroidal diseases, including cone dystrophy, central areolar choroidal dystrophy, Stargardt's disease and fundus flavimaculatus, and in chloroquine retinopathy. The relatively mild colour vision defect with no photophobia, a normal photopic electroretinogram, and well preserved choroidal vessels may exclude the diagnosis of cone dystrophy and central areolar choroidal dystrophy, ${ }^{356}$ and chloroquine retinopathy is also excluded by the patients' history. Stargardt's disease is an autosomal, recessively inherited, juvenile macular degeneration, in which the macula is involved primarily, but white or yellowish white flecks similar to those found in fundus flavimaculatus are deposited frequently in the deep retina of the posterior fundus,,$^{36 x}$ and those flecks were described in at least some of the patients of Stargardt's original report. ${ }^{9}$ Although case 1 showed at the initial visit only a small number of faint fleck lesions, characteristic flecks became conspicuous and increased in number during a follow-up period of 14 months. So fundus flavimaculatus with macular involvement may be the correct diagnostic term for this case.

Since the siblings are children of consanguineous, healthy parents, it may be certain that their disease was caused by the same autosomal recessive gene, and their retinal change represents a marked polymophism in fundus flavimaculatus.

\section{References}

1 Franceschetti A. Ueber tapeto-retinale Degenerationen in Kindesalter. Entwicklung und Fortschritt in der Augenheilkunde. Stuttgart: Enke, 1953.

2 Franceschetti A, François J. Fundus flavimaculatus. Arch Ophtalmol (Paris) 1965; 25: 505-30.

3 Deutman AF. Macular dystrophics. In: Goldberg MF cd. Genetic and metabolic eye disease. Boston: Littlc, Brown, 1974: 367-429.

4 Klcin BA, Krill AE. Fundus flavimaculatus: clinical, functional and histopathologic observations. Am J Ophthalmol 1967; 64: $3-23$.

5 Koyama Y, Ohba N. Cone dystrophy-report of 18 cases. Folia Ophthalmol Jpn 1982; 33: 2401-5.

6 Dcutman AF. The hereditary dystrophies of the posterior pole of the eye. Assen: Van Gorcum, 1971.

7 Fishman GA. Fundus flavimaculatus. A clinical classification. Arch Ophthalmol 1976; 94: 2601-7.

8 Noble KG, Carr RE. Stargardt's discase and fundus flavimaculatus. Arch Ophthalmol 1979; 97: 1281-5.

9 Stargardt K. Über familiärc, progressive Degeneration in der Makulagegend des Auges. Graefes Arch Klin Exp Ophthalmol 1909; 71: 534-50. 